Bulletin UASVM Food Science and Technology 70(2)/2013, 151-152

ISSN-L 2344-2344; Print ISSN 2344-2344; Electronic ISSN 2344-5300

\title{
The Influence of Stunning Method, Refrigeration and Freezing Time on the Rheological and Textural Properties of Raw Meat
}

\section{Liliana TUDOREANU}

Interdisciplinary Laboratory for Heavy Metals Accumulation in the Food Chain and Modelling. Faculty of Land Reclamation and Environmental Engineering, University of Agronomic Sciences and Veterinary Medicine of Bucharest. Bd Marasti 59 sect 1 Bucuresti, Romania; liliana_tudoreanu223@hotmail.co.uk

\begin{abstract}
The present research was conducted to provide information on the influence of stunning methods in conjunction with refrigeration and freezing time on the textural and rheological properties of raw pork meat. Textural properties such as hardness, cohesiveness, adhesiveness and fracture force of raw pork meat was analysed for fresh meat, after 3 days of refrigeration, 15 days, 30days and 60 days freezing time. Meat hardness increased sharply after 3 days of refrigeration and showed no significant differences after 15days of freezing compared to 3days refrigeration time. The meat hardness decreased significantly after 30 days of freezing compared to samples freezed for 15 days. The hardness of meat samples from gas stunned animals was 2.57 times higher, compared to the hardness of meat from electrical stunned animals.
\end{abstract}

Keywords: raw meat, texture, freezing time, stunning method

Introduction. Rheological properties, including texture of raw meat, are highly dependent on its microstructure and composition. Previous researches conducted on row meat showed that the microstructure and composition is influenced by: muscle structure, muscle proteins, connective tissue proteins and sarcoplasmatic proteins, by the physical and chemical changes during rigor mortis, pre-slaughter treatments, breed, sex, nutritional stress, growth promoters, fatness, methods of slaughter, post-slaughter treatments (Choi, 2012; Insausti et al., 2012; Lorenzo et al., 2013). Moreover several mechanical test such as Warner-Bratzler shear force appeared to be a good predictor of the tenderness for grill-cooked pork (Alonso et al., 2010).

Aims and objectives. The present research aim is to provide information on the influence of stunning methods in conjunction with refrigeration and freezing time on the textural and rheological properties of raw meat. The research objectives are: a) to identify any significant differences between textural properties of raw refrigerated pork meat from a animals slaughtered using different stunning methods; b) to identify any significant differences of textural properties in raw pork meat induced by freezing time; c) to identify the influence of the stunning methods on the textural properties of freeze raw pork meat.

Materials and methods. The samples for this research were bought from the local markets. The longissimus dorsi (LD) muscles from 6 different animals, which were before slaughter stunned by electrical stunning (ES) and by gas stunning (GS), were cut into four sections along to the cross sectional area. For comparison between ES and GS meat, similar sections of each muscle were analyzed. Samples of 30mmx30mmx30mm were cut from each section before analyses and 20 to 30 samples were obtained from each section. Measurements were conducted at $20{ }^{0} \mathrm{C}$. Sample were analyzed as fresh (the same day they were bought from the market), after 3 days of refrigeration $\left(6{ }^{0} \mathrm{C}\right)$, and after 15 days, 30days and 60 days freezing 
time $\left(-22^{0} \mathrm{C}\right)$ in commercially available refrigerators. Hardness, cohesiveness, adhesiveness and fracture force were measured for $30 \%$ deformation by double compression using a plate jig and a Volodkevich Jig on a Universal Texture Analyser TA-PLUS (Lloyd) with Nexigen Software. Statistical analyses were performed using the JMP software (SAS Company).

Results and Discussion. The GS samples had the highest coefficient of variance for all rheological parameters regardless the time of refrigeration. The hardness of the raw pork meat from gas stunned animals was 2.57 times higher compared to raw pork meat from electrical stunned animals indicating a better firmness of the gas stunning raw pork meat (Tab. 1). The cohesiveness of the raw pork meat from gas stunned animals maintained its levels after 60 days of freezing while the meat from electrically stunned animals showed significant modification.

Tab. 1

Textural properties for ES and GS meat. Results from a double compression test for 30\% deformation. (Mean values \pm standard deviations). Values followed by the same letter are not significant for $\alpha=0.05$. Value can be compared only by rows.

\begin{tabular}{|l|c|c|c|c|}
\hline \multirow{2}{*}{ Textural parameter } & \multicolumn{2}{|c|}{ Refrigerated } & \multicolumn{2}{c|}{ 60 days freezing } \\
\cline { 2 - 5 } & ES & GS & ES & GS \\
\hline Hardness $(\mathrm{N})$ & $1.711 \pm 1.105 \mathrm{a}$ & $4.399 \pm 4.024 \mathrm{~b}$ & $2.289 \pm 1.809 \mathrm{c}$ & $11.103 \pm 20.268 \mathrm{~d}$ \\
\hline Cohesive-ness & $0.308 \pm 0.044 \mathrm{a}$ & $0.324 \pm 0.0817 \mathrm{~b}$ & $0.351 \pm 0.049 \mathrm{c}$ & $0.320 \pm 0.048 \mathrm{~b}$ \\
\hline Adhesiv-ness $(\mathrm{Nmm})$ & $0.228 \pm 0.205 \mathrm{a}$ & $0.321 \pm 0.230 \mathrm{~b}$ & $0.546 \pm 0.396 \mathrm{c}$ & $0.602 \pm 0.419 \mathrm{~d}$ \\
\hline Fracture force $(\mathrm{N})$ & $1.529 \pm 1.062 \mathrm{a}$ & $3.913 \pm 3.997 \mathrm{~b}$ & $2.094 \pm 1.192 \mathrm{c}$ & $9.72 \pm 17.827 \mathrm{~d}$ \\
\hline
\end{tabular}

Tab. 2

Textural properties (mean value \pm standard deviation) rafter a double compression test using a Volodkevich Jig for ES meat. Deformation 30\%

\begin{tabular}{|l|c|c|c|c|}
\hline \multicolumn{1}{|c|}{ Textural parameter } & Fresh & $\begin{array}{c}\text { 3days refrigeration } \\
(6 \mathrm{C})\end{array}$ & $\begin{array}{c}15 \text { days freezing } \\
(-22 \mathrm{C})\end{array}$ & $\begin{array}{c}30 \text { days freezing } \\
(-22 \mathrm{C})\end{array}$ \\
\hline Hardness $(\mathrm{N})$ & $9.283 \pm 1.106$ & $32.086 \pm 8.778$ & $33.4 \pm 8.4$ & $15.8 \pm 1.51$ \\
\hline Cohesive-ness & $0.129 \pm 0.017$ & $0.122 \pm 0.02$ & $0.14 \pm 0.02$ & $0.13 \pm 0.02$ \\
\hline Fracture Force $(\mathrm{N})$ & $8.741 \pm 1.048$ & $20.995 \pm 8.441$ & $16.2 \pm 11.5$ & $13.2 \pm 4.41$ \\
\hline Adhesive-ness $(\mathrm{Nmm})$ & $0.15 \pm 0.092$ & $1.097 \pm 0.686$ & $0.26 \pm 0.17$ & $0.22 \pm 0.25$ \\
\hline
\end{tabular}

Conclusions. (1)Freezing time has a major influence on textural properties of raw meat. To improve the consumer's awareness on meat quality, recommendation on best freezing time could be made. (2)Stunning methods is influencing the textural properties of raw meat and also influence its textural properties during freezing.(3) The large variability of the textural properties suggest the need for a large number of individual carcasses to be tested for generating statically robust conclusion on the textural properties modifications due to stunning methods

\section{REFERENCES}

1. Alonso, V., Campo, Maria del Mar, Provincial, L., Roncalés, P., and Beltrán J. A. (2010) Effect of protein level in commercial diets on pork meat quality. Meat Science. 85: 7-14

2. Choi, Y.M., Jung K.C., Choe J.H. and Kim, B.C. (2012). Effects of muscle cortisol concentration on muscle fibber characteristics, pork quality, and sensory quality of cooked pork. Meat Science. 91 (4): Pages 490-498

3. Lorenzo, J. M., Sarriés, M. V. and Franco, D. (2013). Sex effect on meat quality and carcass traits of foals slaughtered at 15 months of age. Animal. 7 (07): 1199-1207.

4. Insausti, K., Beriain, M. J., and Sarries M.V. (2012). Physical properties of meat and meat products. Measurement Techniques and Applications in Physical properties of foods edited by Arana I. CRC Press. 